Original Research Paper

\title{
A Study on Standardization of Training Process in Titan Industries Limited- Precision Engineering Division, Hosur
}

\author{
${ }^{1} \mathrm{~J}$. Shanmuganathan and ${ }^{2} \mathrm{~S}$. Thiriveni Sripriya \\ ${ }^{1}$ GITAM School of Business, GITAM Deemed to be University, Bengaluru Campus, Karnataka, India \\ ${ }^{2}$ Jansons School of Business, Coimbatore, Tamilnadu, India
}

\author{
Article history \\ Received: 19-11-2019 \\ Revised: 09-12-2019 \\ Accepted: 27-12-2019 \\ Corresponding Author: \\ Dr. J. Shanmuganathan \\ GITAM School of Business, \\ GITAM Deemed to be \\ University, Bengaluru Campus, \\ Karnataka, India \\ Email: jeysh_423@yahoo.com
}

\begin{abstract}
Training is an effective method for enhancing the knowledge and skills of workforce in any industry and it is a critical aspect for development of organization as a whole. The objective of this study is to assess the training process and adopted a suitable method to standardize the process. In the globalised era, organizations need to update the knowledge; skill and ability of their human resources throughout the year on continuous basis and the organization should ready to spend a nominal amount of money for the purpose of training and development of their workforce. The study was done in Titan industries - PED division, to understand the effectiveness of training process and methods of training are standardized. The study is conducted among the workforce of the company and employees express their opinion regarding the effectiveness of training process in their organization. The study results conclude that their training programme are relevant and appropriate as per the policies and procedures of an organization and execute the training programme in effective manner.
\end{abstract}

Keywords: Training Process, Standardization, Effectiveness, Titan - PED

\section{Introduction}

Every organization needs to have well trained and experienced people to perform the activities that have to be done. Training is necessary to raise the skill levels and increase the versatility and adaptability of employees. Training is a process of learning a sequence of program behaviour. It is application of knowledge; it gives people an awareness of rules and procedures to guide their behaviour. It attempts to improve their performance on the current job or prepare them for an intended job. Manpower service commission defines training as "a planned process to modify attitude, knowledge or skill, behaviour through learning experience to achieve effective performance in an activity or range of activities. Its purpose in the work situation is to develop the abilities of an individual and to satisfy the current and future needs of organization". Too often, training departments have little or no idea how their training relates to the organizational objectives of a company. This could be due partially to trainers' lack of measurement and evaluation skills, which result in measurements that are not valid, reliable or even useful to the management of the company. In order to understand how effective the training processes are, it is very important to study the entire training process itself. Standardizing the training process is a very aspect in training process as it explains how effective an organization can be in terms of training process.

\section{Importance of the Study}

Training is defined as learning that is provided in order to improve the performance on the present job. A person's performance is improved by showing to the master a new or established technology. Training and development programs improve the initiatives and creativity of employees and help prevent manpower obsolescence which may be due to age, temperament or motivation or inability to adapt to technological changes. Indeed, there is an urgent need for deferred application of human resources with special talents with a view to procuring specialized services, which will be required in future. The significant issue is to identify and invest in constantly bigger size applications. Hence for this reason effective training has to be given in order to achieve higher heights in the company. For this reason the training programs are required at a standardized level to achieve good results for the organization. 


\section{Overview of Titan - PED}

Titan Industries Ltd is the world's fifth largest wrist watch manufacturer and India's leading producer of watches. The company is engaged in manufacturing of watches, jewellery, precision engineering and Eyewear. They produce watches under the brand name Titan, Fastrack, Sonata, Nebula, RAGA, Regalia and Octane and Xylys. They export watches to about 32 countries around the world. They manufacture precious jeweller under the Tanishq brand name. Titan Industries Ltd is a joint venture between the Tata Group and the Tamil Nadu Industrial Development Corporation (TIDCO). Titan Industries Ltd was incorporated in the year 1984 and commenced their business in the year 1986. The company set up an integrated watch manufacturing facility at Hosur in Tamil Nadu in the year 1987 with initial technical know-how from Europe and Japan. In October 1992, they came with a right issue to the part of finance for its expansion programs. In the year 1995, they diversified into Jewellery under the brand name of Tanishq to capitalize on a fragmented market operating with no brands in urban cities. Apart from the domestic market, the company started the manufacturing of watches for several prestigious international brands during the year 1997. In the year 1998, the company launched the second watch brand, Sonata.

Precision Engineering Division of Titan was started in 2002. It has become one of the leading manufacturers of Precision Parts Automotive and Aerospace Industries. The Diverse Product range includes pointers, dashboard clusters like Fuel Gauge, Temperature Gauge, Gear Shift Indicators, Clocks for Automobiles and any kind of Injection moulded Plastic parts, Electromechanical Assemblies for automobiles, all kinds of pressed and turned parts for automobiles. The Tooling Sector of Precision Engineering Division manufactures all kinds of Press Tool, Moulds, Jigs and Fixtures for various industries. Titan Automation Solution, a part of Precision Engineering Division is a leading Automation Solution Provider for all kind of industries. They made significant contributions to add value during the product development stages of the low-cost water purifier, Tata swatch, developed by Tata Chemicals. The Automation Solution applied its precision engineering capabilities to supply automation solutions for the development of special assembly presses that enabled mass production of Tata swatch.

\section{Review of Literature}

In any research oriented studies, a decent literature reviews not only provide knowledge about what has been done in the research but also able to understand the strengths and weaknesses on which one can build it's perceptive and focused area of study.

Gopal (2008), in his study he has explored about effectiveness of training for executives. And the factors influence their managerial and decision making skills. The author studied about training policies and procedure that are followed in the organization to train the executives on various managerial skills. The study also assesses the effectiveness of training programme and execution in the organization as the whole. The respondents are supervisor, middle level managers and executives of various departments in relate manufacturing companies. The study is based on primary data method which used questionnaire as a tool for collecting 115 responses. The results conclude that the organization has strong training policies and execute the training programme for the development of their executives in achieving organizational objectives.

Neetu (2008) studied about the usefulness of training programme and thee trainee is able to apply the theoretical aspects of learned concepts into regular practice in their actual work environment. The study highlighted the use of role playing, cases, simulation, interceded exercises and computer based learning to provide exposure on current and relevant field of knowledge and real world situations. The results indicate the significant association on the variables of training programme assessment and method of training adopted in a training programme.

Ahmad and Din (2009) explained in his study about training and development activities followed in organizations to fill the skill gap of employees. The study comprises of training need analysis, training execution, training types, trainer's quality and evaluation method. The study is conducted among the manufacturing companies and 275 samples are collected through questionnaire method. Training and development activities must be appropriate for the employee's skills, Job nature and work environment. Evaluation method followed in some manufacturing companies is not ensuring the effective learning unless training is properly designed and executed. Successful training and development activates depends upon whether the planning and method of evaluation should match the design of the training program before it was executed.

Srimannarayana (2011) considers that Training and Development is an important component of modern HRM practices and the purpose of training and development vary from one organization to another. The study is based on primary data method and collected 105 responses from HR/Training professionals working in manufacturing, IT/ITES and service sector with a 
minimum experience of three years in their respective organization and functional area of training and development. The study revealed that more than $75 \%$ of respondents are believed that training is an important component for performance improvements and $70.48 \%$ of respondents believed that transfer of learning is extremely important in work environment. The maximum respondents $(95 \%)$ convey that feedback has to be collected from participants after completion of training programme on regular basis. There is an assessment gap between the measures that are done by HR/Training professionals on training aspects.

Devi and Shaik 2012 expressed the purpose of the research to identify how training and development influence the employee performance and analyse the impact the training and development variables on organizational effectiveness. Primary data method is used and 286 employees are considered as samples for the study that are collected from different manufacturing organizations. As per the reviews of previous researches, the variable for training and development are selected. Training and development is important for the employees in organization, it helps the employees to improve their skills and to give a better performance in workplace. The result concludes that there is a strong relationship between training and development with employee performance and showed positive impact among the variables of training and development towards organizational effectiveness.

Ramakrishna et al. (2012) highlighted that HRD department has play a proactive role in shaping the employees to defend the challenges in competitive environment. The banks not only formulate the plans and policies and devise strategies but the actual execution shows the competence and effectiveness of achieving organizational objectives. A sample of 85 employees covering all branches of Canara bank in Kurnool District has been considered for the study randomly. The study revealed that the employees have attended more training and development programmes, employees strongly agreed about the necessity of training and development programmes, majority of the employees rated trainer's preparation as good, employees rated trainers creating learning atmosphere and employees given overall rating for training and development programmes.

Arhan (2012) pointed out that the strategic human resource development factors affecting the evaluation of induction training effectiveness in Nepali banks. The study is based on questionnaire survey and 104 samples are collected from low and middle level managers of Nepali development bank. The study revealed that induction training as most effective in terms of learning and least effective on the criteria of behavioural change.

Manisha (2012) explained the existing policies practiced in co-operative banks to appraise the level of HRD practices and to assess the satisfaction level of employees on HRD practices exclusively the variables of training and development and reward and recognition. The study is formulated with structured questionnaire and in-depth personal interviews for collecting the necessary information as a primary source. Selective of 16 banks in Pune region are used for collecting the sample. In each bank, 30 employees of different level are adopted for gathering the information relevant to the study and employees are selected randomly from cooperative banks. The results highlighted that training helps employees to gain knowledge related to job and also enhance their attitude towards work environment. Extensive training programme such as on-the-job training, off -the-job training programmes and workshops gives continuous development and act as a driving factor for better productivity and performance. The study also suggested the method by which the selected co-operative banks can improve their performances in regular practices.

Ajit (2013) described that training and development programmes undertaken in banking sector for their employees. The purpose of the study is to analyse the effectiveness of training and development programmes for employees to discharge their duties and to know how training and development programmes helps to achieve customer satisfaction. The primary data is collected through questionnaire and bank employees are considered as a respondent. A sample of 40 employees is selected randomly from each bank names as HDFC, ICICI, Vijaya bank, Bank of Baroda and Dena Bank located in suburban area of Mumbai. The study concludes that private and public banks which give training and development programmes for their employees are increased and the objective of training programme is fulfilled by increasing the efficiency of employees. Banks provide training programmes to enhance their behavioural attitude which helps to satisfy the customers. Growth of banking sector depends on skilled manpower which is an outcome of training and development.

Nassazi (2013) describes the purpose of this study is to evaluate the effects of training on employee performance in telecommunication industry of Uganda. In his study, he focused particularly in identifying the training programs' existing in the industry. The study is in the form of case studies among telecommunication companies operating in Uganda. A qualitative research approach is used and adopted questionnaire as method of data collection which consists of 18 questions distributed 
to 120 respondents. Based on the sample collected, the results indicate that training have a strong effect on the performance of employees. The findings also describe the HR policies followed for training managers and executives of telecom companies.

\section{Objectives:}

1. To study the effectiveness of training process and ways to standardize it in Titan

2. To understand the training process followed in Titan's Precision Engineering Division.

3. To understand the needs of the employees in order to standardize the training process in Titan

\section{Research Methodology}

The research paper is descriptive in nature and primary method of data collection through questionnaire is used to gather the information among employees of Titan - PED, Hosur plant. The secondary data includes reference books, journal, research papers and internet. Simple random sampling method is used to collect the samples of 200 from 540 employees working in the company. The task of data collection begins after a formulating the research problem and defined research plan is designed to understand the objective.

\section{Analysis and Findings}

Table 1: Percentile analysis

\begin{tabular}{|c|c|c|c|}
\hline Q. No. & Parameters & $\begin{array}{l}\% \text { of } \\
\text { Response }\end{array}$ & Description \\
\hline Q 1 & Induction training is given adequate importance. & $86 \%$ & Agree \\
\hline Q 2 & Regular training programmes are conducted as per planned. & $85 \%$ & Very good \\
\hline Q 3 & Scheduling of training programme have enough period to learn & $78 \%$ & Good \\
\hline Q 4 & Training policies and procedure are followed in every programme & $80 \%$ & Agree \\
\hline Q 5 & Training programmes are reviewed periodically and improved & $90 \%$ & Agree \\
\hline Q 6 & Training programme fulfils the requirements of employee's needs. & $84 \%$ & Good \\
\hline Q 7 & Training programme gives sufficient content and Material & $78 \%$ & Very Good \\
\hline Q 8 & Training methods are followed as per the requirements of content and audience & $65 \%$ & Agree \\
\hline Q 9 & Sufficient training environment is provided for the programme & $90 \%$ & Very Good \\
\hline Q 10 & Training programme helps to learn real world problems and participatory mode. & $76 \%$ & Good \\
\hline Q 11 & Training gives better skills relevant to the job & $82 \%$ & Agree \\
\hline Q 12 & Training enhance the work efficiency and effectiveness of job performed by employees. & $76 \%$ & Agree \\
\hline Q 13 & Training programme are evaluated through proper scale and results are measured. & $90 \%$ & Agree \\
\hline Q 14 & Training process are standardized for all levels of job & $82 \%$ & Agree \\
\hline Q 15 & Training help employees to perform well and results with promotion and other monetary benefits. & $80 \%$ & Agree \\
\hline
\end{tabular}

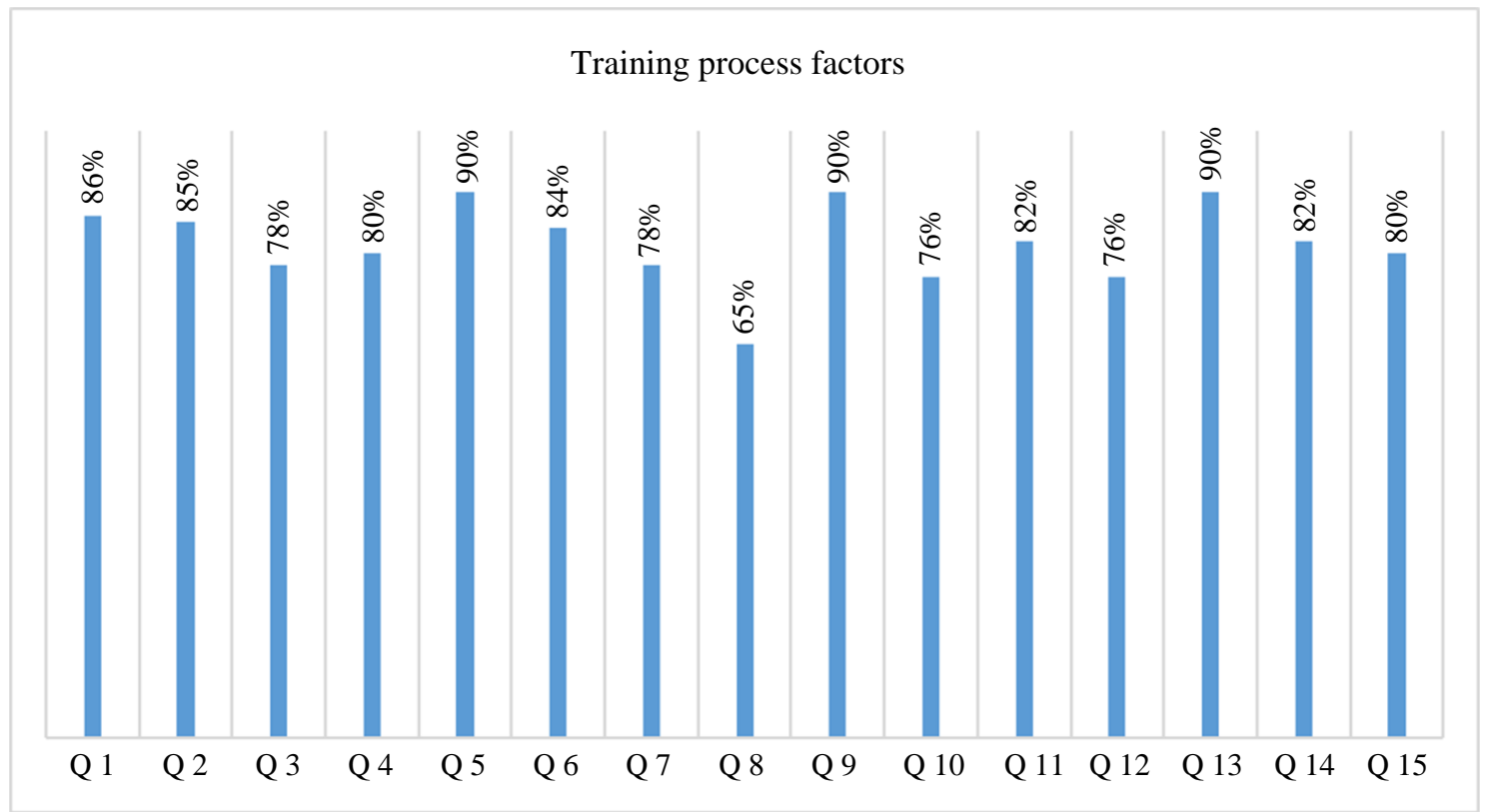

Fig. 1: Factors influencing training process 
The Table 1 indicates the parameters that are used to assess the standardized level of training programme in the organization. As a whole, percentile value of the variables is above $75 \%$, which revealed that the company have structured policies and procedure for training programmes at all levels of management. The majority of employees $(70 \%)$ gave the positive opinion on various factors (displayed in the Table 1) towards the training programme organized for their development of performance. Figure 1 represents the graphical format of entire training process practiced in the company.

\section{Interpretations:}

- The training process followed in Titan PED is considerably good as the respondents feel that the coordination from the HR department and the also the choosing of trainer is good

- The training need analysis undertaken in the company has a higher success rate, which shows that the employees' expectations are met in terms of their need identification

- Nearly half of the respondents were not aware of the online training calendar, it has not reached them due to some reason. Apart from this there can be a physical training calendar too

- When it comes to execution of training in Titan PED many are able to implement what they learn but not all the time, important training programs can have a follow up so that it might help them to implement the learning

- Many employees are either partially or fully dependent on their superiors or colleagues even after attending training programs

- The follow up training is required by half the population mainly for technical trainings

- Many respondents felt that their training expectations are met by the organization but they have put forth certain constraints in attending training

\section{Conclusion}

Training is a primary source of any organization to develop the knowledge, skills and abilities of their workforce. There is enough evidence to show that employees who are trained on a regular basis would produce a better productivity and performance for their organization. To develop an integrated the standard training process in an organization, we need better policy and culture along with strategy to implement adhoc training and development programs. In a manufacturing industry, employees are most important assets and their development in respective field will yield a sustainable growth in the competitive arena. The study concluded that Titan - PED, Hosur plant has well defined structure of training and development programmes for their employees and following standardized process of training to enhance the efficiency of their employees.

\section{Acknowledgment}

The special thanks to the Management, Executives and Employees of Titan Industries Limited- Precision Engineering Division, Hosur. I acknowledge my supervisor Dr. A. Somu, who supports me in enhancing research skills and all friends in academia.

\section{Author's Contributions}

We got the opportunity to do a programme for the executives and employees in the company for developing certain procedural documents to enhance the standards on work system. During the programme, we conducted certain survey among the employees on different parameters of training and discussed our findings with the concern executives of a company.

\section{Ethics}

We ensure that the content present in this article are the original work of an authors and contains unpublished material. The article submit for the publication is carefully read by author and approve for publication. There are no ethical issues involved in publishing this article.

\section{Reference}

Ahmad, I. and S. Din, 2009. Measuring the effectiveness of training and development program in manufacturing companies. Indian J. Commerce, 62: 86-90.

Ajit, J., 2013. A study on training and development in Indian Banks. J. Res. Commerce Manage., 1: 34-39.

Arhan, S., 2012. Strategic factors in evaluation of induction training effectiveness an exploratory study of Nepali bank managers. EXCEL Int. J. Multidisciplinary Manage. Stud., 2: 16-32.

Devi, R.V. and N. Shaik, 2012. Training and development-a jump starter for employee performance and organizational effectiveness. Int. J. Soc. Sci. Interdisciplinary Res., 1: 202-207.

Gopal, 2008. Effectiveness of executive training programs. Indian J. Commerce, 6: 143-150. 
J. Shanmuganathan and S. Thiriveni Sripriya / American Journal of Economics and Business Administration 2020, Volume 12: 36.41 DOI: 10.3844/ajebasp.2020.36.41

Manisha, P., 2012. An evaluation of HRD practices followed in co-operative banks in Pune region. Int. Multidisciplinary Res. J., 2: 186-195.

Nassazi, A., 2013. Effects of training on employee performance. Evidence from Uganda, Business Economics and Tourism.

Neetu, P., 2008. Corporate training programme- an effective instrument for organization. Indian $\mathrm{J}$. Commerce, 61: 113-119.
Ramakrishna, G., Kamleshwari, M.G. Kumar and C.H. Krishnudu, 2012. Effectiveness of training and development programmes-a case study of Canara bank employees in Kurnool District. Int. J. Multidisciplinary Res., 2: 150-162.

Srimannarayana, M., 2011. Measuring training and development. Indian J. Industrial Relat., 47: 117-125. 